\title{
A juventude na ótica de policiais: a negação do direito na aparência
}

Carlos Angelo de Meneses Sousa Candido Alberto da Costa Gomes Universidade Católica de Brasília

\section{Resumo}

Este trabalho apresenta os resultados de uma pesquisa destinada a melhor estruturar os cursos sobre Juventude e Direitos Humanos aos membros do Batalhão Escolar da Polícia Militar do Distrito Federal, Brasil. 0 estudo, fundamentado na literatura sobre o comportamento policial e suas relações com a juventude, se baseia num questionário respondido por uma amostra não probabilística de 132 policiais militares, correspondente a $18,5 \%$ do citado Batalhão. Na visão dos policiais, o jovem é melhor caracterizado pela moda e aparência, assim como por características predominantemente negativas, entre outras a insegurança pessoal e social; a falta de perspectivas; ser transgressor/ousado; ser instável emocionalmente e egoísta. Estas percepções tenderam a ser mais ocorrentes em policiais de menor escolaridade e idade.

Palavras-chave: Juventude. Polícia. Direitos Humanos. Violência. 


\section{Youth as seen by police officers: denial of the right to appearance}

This paper presents the results of a research project, the main goal of which is to contribute for the improvement of courses on Youth and Human Rights offered to the members of the School Battalion of the Military Police in the federal capital of Brazil, Brasilia. This study is based on the literature on policemen's behavior and their relationship with youth. A nonrandom sample of 132 policemen, or $18.5 \%$ of the universe, responded to a questionnaire. According to the most frequent replies, youth were best characterized by fashion and appearance, as well as by predominantly negative characteristics, such as social and personal insecurity, lack of perspectives, being transgressors/bold, and being emotionally unstable and selfish. These perceptions tended to be more frequent among younger and less educated officers.

Keywords: Youth. Police. Human Rights. Violence.

\section{La juventud bajo la visión de Policías: la negación del derecho en la apariencia}

Este trabajo muestra los resultados de una investigación que tiene como destino mejorar la estructura de los cursos de Juventud y Derechos Humanos que son impartidos a los miembros del Batallón Escolar de la Policía Militar del Distrito Federal, Brasil. El análisis tiene como base la literatura del comportamiento de la policía y sus relaciones con la juventud. Los cuestionarios fueron respondidos por una muestra no probabilística de 132 policías militares. Para los policías, el joven es caracterizado mejor por su apariencia y la moda, como también por características predominantemente negativas, entre ellas, la inseguridad personal y social, la falta de perspectivas, ser transgresor/inconsecuente, ser inestable emocionalmente y egoísta. Estas percepciones fueron más frecuentes entre los agentes con menor nivel de escolaridad y menos edad.

Palabras clave: Juventud. Policía. Derechos Humanos. Violencia. 


\section{Introdução: polícia e juventude}

Polícia e juventude tendem a se situar em pólos opostos: enquanto os jovens vivem um processo de liberação e são recém-chegados ao protagonismo, na perspectiva de lanni (1968), a polícia tem o papel de manter ou estabelecer a ordem. Esta oposição é anterior ao movimento social juvenil de 1968, que começou na França e se espalhou por grande parte do mundo ocidental como o fogo atiçado pelo vento, inclusive no Brasil com os protestos contra o governo militar. Compreende-se como juventude, do ponto de vista demográfico, pelos padrões internacionais, o grupo etário de 15 a 24 anos de idade, no Brasil estendidos pelo Instituto de Pesquisa Econômica Aplicada (IPEA) da Presidência da República até os 29 anos (Gomes, 2011). Embora necessários, os limites estatísticos podem não coincidir com as características socioculturais da conquista da identidade, da busca do estudo e do trabalho e da transição não raro adiada para a idade adulta (Galland, 1997). Como alvo da propaganda e do marketing da sociedade de consumo, seus contornos variam conforme o local e o tempo, todavia, apesar do fascínio exercido, trata-se de um grupo vulnerável, caracterizado internacionalmente pelas dificuldades de obtenção de trabalho, em especial de trabalho decente, pelo nível de pobreza e pela exposição à violência, quer como vítima, quer como autor ou testemunha. A chamada geração ni-ni (ni trabaja, ni estudia) corresponde à fração do grupo que, em geral após inúmeras tentativas, desiste do estudo e do trabalho.

Em face dessa múltipla vulnerabilidade, é muito relevante estudar a relação entre juventude e polícia no Brasil, ainda mais no que se refere à violência (Waiselfiszz, 2004; Waiselfisz et al., 1998), que se esparrama desde as relações com o crime organizado até as rixas entre jovens bem ou mal nascidos que defendem a sua territorialidade. Chega também às escolas, onde estudantes são vítimas e autores de violências, tornando o ambiente pouco propício para a educação, no sentido formativo, e para a aprendizagem.

Esta oposição latente ou real entre juventude e polícia é documentada pela literatura internacional. Muitas pesquisas mostram a relação, no imaginário social, entre juventude, violência e perigo. Não por acaso, percepções de jovens urbanos sobre a polícia no Brasil são negativas, inclusive como alvos preferenciais de abordagens (cf. Minayo et al., 1999; Abramovay et al., 1999). Na Argentina, com a repressão dos governos militares, configurou-se a imagem dos jovens como inimigos internos perigosos. Antes associados ao protesto político, foi incorporada aos jovens a construção social do criminoso, o que, num círculo vicioso, legitima ações autoritárias e discriminatórias das quais têm resultado mortes e ferimentos de jovens, inclusive o chamado Masacre de Ingeniero Budge, com grandes repercussões midiáticas (Nuñes, 2006). Uma pesquisa com estudantes de Direito no México, mesmo após ampla reforma da polícia, evidenciou a 
persistência do medo e outras percepções negativas dos jovens, mesmo em classes sociais mais favorecidas (Brown; Benedict; Wildinson, 2006).

Num país de latitude bem diferente, a Austrália, Copeland (2008) constatou que o sistema social e legal funciona no sentido de reduzir a participação cívica de crianças e jovens, o que representa uma redução dos seus direitos humanos. Com as percepções de que os jovens são indisciplinados e perigosos, estes constituem alvos prioritários da abordagem e outras formas de intervenção policial. Como a corda arrebenta do lado mais fraco, migrantes e minorias étnicas/raciais são ainda mais prioritários no conjunto de jovens. Outra pesquisa que corrobora esses dados sobre a abordagem policial, desproporcional e discriminatória com relação aos negros, foi realizada na Inglaterra e País de Gales, onde se constatou estatisticamente que esse grupo é até seis vezes mais abordado do que outros (Bowling; Phillips, 2007).

Muitas outras investigações nos Estados Unidos constatam que jovens de menor renda e de minorias étnicas/raciais (características que costumam unir-se) são mais vulneráveis aos contatos com a polícia e percebem mais intensamente a injustiça criminal (Hagan; Shedd; Payne, 2005). As contestações usuais destas constatações afirmam que tal vulnerabilidade se deve à associação proporcional à criminalidade. Entretanto, Gelman, Fagan e Kiss (2005) verificaram que descendentes de africanos e hispânicos foram abordados mais frequentemente que brancos pela polícia de Nova lorque, mesmo depois de controlar a relação por distrito policial e por estimativa de participação criminal por raça/etnia. Compreende-se que o contato preferencial da polícia com determinados grupos envolve critérios de eficiência, isto é, aparentemente haveria maior probabilidade de detectar infrações e infratores. Todavia, como o estigma social e étnico-racial é colado a esses grupos, existem também as probabilidades de controlar mais certos setores da população e de negligenciar outros, que podem aproveitar-se precisamente dessa hierarquia de prioridades. Como quem procura, acha, identificam-se tais grupos como os mais violentos, levando a uma superestimativa dos seus atos em desacordo com a lei. Daí pode ocorrer o conhecido efeito da profecia autorrealizadora (Rist, 1978; Hurst; McDermott; Thomas, 2005).

A literatura revela, porém, abundantes evidências sobre algumas características do melhor profissional das polícias. De um lado, há evidências de que a prática e a experiência são mais importantes. De outro, constata-se que o grau de escolaridade tem maior impacto, dando ênfase à formação científica. Por exemplo, pesquisas mostram que policiais com educação superior são mais bem avaliados pelo público, menos autoritários, têm maior capacidade de expressão, fazem menor uso da força física e da coerção verbal, entre outras características (Paoline III; Terrill, 2007). A discussão não é conclusiva, mas têm se salientado duas variáveis relevantes da formação com impacto significativo sobre a atuação do policial: a experiência versus o grau de escolaridade. 
No caso das redes escolares, em diversos países do mundo, a polícia tem papéis mais ou menos bem definidos, como, no caso do Distrito Federal, o Batalhão Escolar da Polícia Militar (PM). A Universidade Católica de Brasília e a UNESCO, a pedido, estruturaram e ofereceram cursos sobre Juventude e Direitos Humanos ao mencionado Batalhão, primeiro para os oficiais e, avaliados os resultados, depois para os praças, como alternativa para tornar mais efetivas as suas ações nas escolas públicas. Para instruir os próprios cursos, foi desenvolvida uma pesquisa junto aos cursistas para melhor conhecer como os jovens e adolescentes apareciam através das suas lentes. A pesquisa teve como objetivos:

a) Identificar as características sociais dos respondentes e as suas expectativas em relação ao curso;

b) Analisar as características mais relevantes dos jovens, na sua perspectiva, as relações com a autoridade, no sentido amplo, com a polícia e a lei;

c) Caracterizar as percepções dos policiais militares quanto à juventude em relação às suas principais características e

d) Relacionar características sociais dos respondentes, significativas de acordo com a literatura, às percepções dos jovens.

Existem pesquisas que focalizam as percepções do jovem sobre a polícia, inclusive no Brasil, porém são escassas as que retratam as percepções da polícia sobre o jovem. A identificação dessas imagens, refletidas pelos espelhos dos diferentes papéis sociais desempenhados, é uma condição para o terceiro pilar da educação para o século XXI, segundo a UNESCO: aprender a conviver (Delors et al., 2000). Esta é a luz, pelo menos de vaga-lume, que a pesquisa pretendeu projetar.

\section{Procedimentos metodológicos}

Em termos metodológicos, foi aplicado um questionário para a coleta de dados junto aos policiais militares (PMs) em 2008. Para elaboração desse instrumento, consideraramse as características e os objetivos da investigação e se optou por um tipo misto, alternando questões abertas e fechadas, que proporcionou assertivas capazes de dar ao inquirido maior liberdade de resposta às questões abertas, ao mesmo tempo em que permitiu a hierarquização e a tipificação das informações a partir da utilização de modelos escalares. Quanto às escalas, nominais ou classificadoras, foram utilizadas de forma mista e adaptada as do tipo Likert e Guttmann. Os questionários foram respondidos por uma amostra não-probabilística de 132 policiais militares da segunda turma do curso sobre Juventude e Direitos Humanos oferecido aos membros do Batalhão 
Escolar da Polícia Militar do Distrito Federal pela Cátedra UNESCO de Juventude, Educação e Sociedade da Universidade Católica de Brasília. Esse número correspondia, no período da coleta de dados, a aproximadamente $18,5 \%$ do efetivo lotado no âmbito do Batalhão Escolar da Polícia Militar (PM - DF). A tabulação dos dados se deu com auxílio do software Microsoft Excel.

Neste artigo faremos uma exposição parcial dos dados e análises da pesquisa, centrando nosso foco na visão dos policiais militares sobre o que mais caracteriza atualmente a juventude. Para tanto, sempre que pertinente destacaremos os resultados com base nas variáveis mais relevantes segundo a literatura internacional, isto é, as variáveis de gênero, faixa etária, nível de escolaridade e tempo de serviço na PM.

\section{Quem são os policiais militares?}

Na caracterização dos respondentes, verificou-se que o grupo foi constituído predominantemente por homens, $91,8 \%$, e $8,2 \%$ de mulheres, com alta representação de jovens, correspondendo a $36,6 \%$ até 29 anos, $35,8 \%$ de 30 a 36 e $27,6 \%$ de mais de 36 anos. 0 nível de escolarização era alto, tendo $58,0 \%$ cursado o ensino médio completo e os demais, $42 \%$, o curso superior de graduação e/ou pós-graduação.

0 tempo de serviço na PM dividiu-se em cerca de um terço de até sete anos, um terço de oito a 13 anos e, ainda, outro terço com mais de 13 anos. Cerca de um quinto dos participantes não integrava o Batalhão Escolar, enquanto 44,8\% dos PMs lá estavam há até seis anos, e 32,1\% há mais de seis anos. Em relação à patente, verificou-se que a maioria, correspondendo a $71,9 \%$, era de soldados, enquanto $15,1 \%$ eram cabos e $13,0 \%$, oficiais e suboficiais. A mais alta expectativa em relação ao curso foi a de aperfeiçoar o desempenho profissional e a menor, ter possibilidade de promoção.

Verificou-se, portanto, um grupo de alta escolaridade relativa, com experiência, motivado, e em parte jovem. Tais características, se comparadas à literatura existente, demonstram uma interessante associação entre as variáveis experiência, grau de escolaridade e motivação.

\section{0 que mais caracteriza a juventude para os policiais militares}

Frente às opções a moda e a aparência; a força e a agilidade; a linguagem; a música; a consciência, a responsabilidade e o compromisso; a insegurança pessoal e social; a falta de perspectivas; ser transgressor/ousado; ser instável emocionalmente; ser criativo/empreendedor e ser egoísta, os policiais militares foram indagados sobre qual 
ou quais das mencionadas características melhor define $(m)$ o jovem dos dias de hoje, devendo assinalar em ordem crescente até três características.

Verificou-se que a característica mais apontada pelos PMs, para melhor caracterizar o jovem hodiernamente, foi a moda e a aparência, com 32,3\%, ou 42 respondentes. Cotejando esse dado com o nível de escolaridade dos PMs, observamos que, dentre os respondentes com educação superior, $29,6 \%$ consideraram que a moda e a aparência estava em primeiro lugar, enquanto que, junto aos respondentes com ensino médio, este índice subiu para 37,2\%. Assim, confirmando uma vertente da literatura, verificase a relação inversamente proporcional entre o grau de escolaridade e a indicação da opção da moda e da aparência como o que mais define o jovem, isto é, quanto menos escolaridade, mais se caracteriza a juventude a partir da moda e da aparência, ou seja, por marcas externas e ostensivas.

Tomando como variável independente a idade dos respondentes, chama atenção o fato de $50 \%$ dos PMs de até 29 anos de idade situarem moda e aparência entre as três características mais importantes, enquanto que, dentre os PMs maiores de 36 anos de idade, esta característica foi apontada por somente 18\%. Esses dados nos sugerem que a idade do PM é importante para a inclusão da moda e aparência entre as três características que melhor definem o jovem dos dias de hoje.

Em relação ao tempo de corporação, 34,1\% dos PMs com até nove anos de corporação apontaram em primeiro lugar a moda e aparência, enquanto que, dentre os PMs com mais de 17 anos de corporação, 53,3\% indicaram essa opção. Podemos inferir que, quanto maior o tempo de corporação, mais acentuada é a indicação da moda e aparência como definidora do jovem nos dias atuais, também ratificando parte da literatura. Há notoriamente, nesses dados, indicadores de uma influência da instituição militar em seus processos de formação e socialização formal e informal, em algum grau, para o endosso dessa visão.

Pensando teoricamente sobre esse dado de caracterização da juventude pelos PMs, a partir da moda e aparência, podemos observar possíveis relações entre o binômio: 0 vestuário, a roupa versus a ordem, a organização ou o primeiro versus a desordem, a desorganização. Vejamos: a roupa gera uma boa ou má aparência social. Ela permite a criação de aparências padronizadas ou não. Em tempos como o nosso, em que há uma forte tendência a processos massificantes, a roupa, especialmente para os jovens, em suas constituições individual e grupal, representa um modo de expressar sua forma de ser, seu estilo, tanto se diferenciando dos outros quanto se identificando com outros. A vestimenta, em sociedades complexas, tornou-se um fator de diferenciação sociocultural, isto é, o que chamamos de moda possui uma lógica própria que comunica costumes e ideais a respeito do mundo. 
Stallybrass (2000) e Lehnert (2000) mencionam que o vestuário é um instrumento que nos possibilita o conhecimento da história de um povo, suas hierarquias e relações internas e externas. 0 vestir-se constitui-se num fato social que cria, no adorno da corporalidade, simbologias que, por sua vez, geram leituras, tanto do sujeito criador do estilo quanto dos outros, da sociedade. 0 mesmo se aplica às marcas de identificação na própria pele, como os piercings, as tatuagens ou as escarificações, consideradas por Pommereau (2006) como a linguagem do indizível.

Ampliando nosso olhar, Marshall Sahlins nos lembra que a moda alimenta tanto o sistema capitalista quanto a sua estrutura simbólica; o autor acrescenta:

Em sua dimensão econômica, esse projeto [das estruturas simbólicas] consiste na reprodução da sociedade num sistema de objetos não simplesmente úteis, mas significativos, cuja utilidade realmente consiste em uma significação. [...] "Mera aparência” deve ser uma das mais importantes formas de manifestação simbólica na civilização ocidental. Porque é através de aparências que a civilização transforma a contradição básica de sua construção num milagre de existência: uma coesa sociedade de estranhos. (Sahlins, 2003, p. 202).

A menção à aparência pelos PMs como forma de caracterizar jovens não é algo fortuito e ocasional em nossa pesquisa. Outras investigações, tendo como objeto de estudo a juventude e a polícia, como a de Silvia Ramos e Leonarda Musumeci, no Rio de Janeiro, asseveram essa visão a partir do expressivo depoimento de um Oficial da PM, entrevistado, ao dizer para os jovens que "procurem melhorar sua apresentação pessoal [...] Arrancar o boné da cabeça, pentear o cabelo, vestir uma roupinha melhor e saber falar". Este mesmo entrevistado, frente aos procedimentos de revista ou "baculejo", construiu uma classificação dos jovens da seguinte maneira: "Se ele [o jovem] tiver essa boa educação, não vai ser parado. Ele tem que [...] ter menos o biótipo do marginal, ter mais o biótipo de cidadão" (Ramos; Musumeci, 2005, p. 218).

Observemos que, conforme esse ponto de vista, a aparência é que faz ver, aos olhos do policial, quem é quem. A aparência ordenada, sem boné, cabelo penteado e roupa melhor transformaria o marginal em um incluído no sistema, o qual deixaria de ter o biótipo do marginal. Assim, o estranho é englobado no sistema de classificação, tornando-se coeso a esta sociedade. Contudo, o jovem em sua individualidade exige a liberdade de expressão e assim explicita a tensão entre o ser individual versus o ser social. A aparência que a moda, o vestuário constrói é realizada para residir nos olhos dos outros.

0 ato de vestir-se de determinados modos informa socialmente, isto é, vestir-se gera mapas de significados sociais, que demandam processos de leitura, de compreensão 
de como os outros interagem conosco socialmente através das aparências. As vestimentas indicam o quê e onde, quem e até mesmo como alguém se coloca frente à sociedade, ao seu grupo social e até a si mesmo. Considerando o todo das relações entre o vestir-se e a sociedade, o sistema de vestuário é “[...] um esquema muito complexo de categorias culturais e de relações entre elas, um verdadeiro mapa - não é exagero dizer - do universo cultural" (Sahlins, 2003, p. 178).

A moda e a aparência através do vestuário, dos adornos criam socialmente movimentos de aproximação estética entre indivíduos, bem como movimentos contrários, de distanciamento, pois há também na moda e na aparência a busca de individualização, de singularidade. Assim, duas lógicas contraditórias se fazem presentes na moda: a lógica de integração e a outra de singularização. Como entendê-las?

Georg Simmel (2005) nos ajuda a compreender essas lógicas aparentemente paradoxais da moda em seus estudos sociológicos sobre a psicologia social da moda. Ele diz que há no ser humano duas necessidades contraditórias: por um lado, a necessidade de integração no geral, que objetiva ser igual aos outros, e, por outro lado, a necessidade de singularidade como tendência à especificidade, que tem como meta a particularidade em contraposição ao todo social.

A perspectiva simmeliana ressalta a importância da referência do indivíduo como construtor do social, embora este se encontre submetido a uma força massificante da sociedade. A moda nesse sentido é o campo de encontro do indivíduo e do social, da singularização e da massificação, descrita como um locus por excelência de disputas dos indivíduos, “[...] os quais não são autônomos no seu íntimo e no seu conteúdo pessoal e necessitam da aprovação social, ao mesmo tempo em que sua auto-estima exige distinção, atenção e o sentimento de ser algo especial" (Simmel, 2005, p. 163).

A juventude, mais do que qualquer outro grupo social, certamente utiliza-se da moda como uma forma de expressão de sua individuação, em termos pessoais e grupais. Convém aqui destacar o interessante fenômeno sociológico que se deu nas sociedades modernas em relação às sociedades tradicionais no que tange à moda e às faixas etárias. Enquanto nestas últimas os mais velhos ensinam aos mais novos os costumes, inclusive do vestuário, nas sociedades modernas há uma mudança, os jovens assumem o protagonismo da orientação, encorajando os mais velhos a olharem para suas criações. Essa nebulosidade das fronteiras entre as gerações contribui para a crise da autoridade e para a constituição de uma sociedade adolescêntrica, segundo as expressões de Guillot (2008). Ou seja, verificam-se sentimentos contraditórios de fascinação e de medo da adolescência e da juventude. 0 primeiro em grande parte é cultivado pela publicidade, ao passo que o segundo deriva de imagens sociais ligadas à segurança pública. 
Indubitavelmente, a relação entre a juventude e a moda é bem mais complexa, e tanto o jovem tem seu papel protagonista quanto a moda, em suas cadeias de consumo, dita regras para o jovem. 0 que importa aqui é destacar que, se por um lado, os jovens, ao aprenderem o idioma da moda, tornam-se mais susceptíveis à publicidade, cheia de imagens da indústria pelas diversas mídias, por outro lado, eles também aplicam "o vernáculo da moda segundo seus próprios termos" e continuam “[...] a usar a roupa como forma de rebelião" (Queiroz, 2002, p. 132). De qualquer modo, conforme Savage (2009), tem sido primordial o papel da sociedade de consumo e da comunicação de massa para tecer histórica e socialmente o conceito de juventude.

Em que esses aportes teóricos iluminam o dado significativo da escolha dos PMs em atribuir em primeiro lugar moda e aparência como o que mais caracteriza o jovem?

Por uma perspectiva, sabemos que as instituições policiais possuem uma formação e processos disciplinares padronizadores de conduta, comportamentos e, inclusive, vestuário (no fardamento), que tendem a estabelecer limites e dificuldades à expressão do que seja individual e singular. Por outro lado, é característico da juventude cultivar justamente esse oposto, isto é, a diferenciação da conduta, comportamentos e vestuário, mesmo que em certos contextos possa padronizar um estilo internamente ao grupo de pertencimento, mas diferenciando-se de outros. A estereotipagem dos PMs, em relação à moda e aparência do jovem a partir de suas visões padronizadoras, tem a potencialidade de gerar processos de conflito e violência nas relações entre estes e os jovens.

Pesquisas no Rio de Janeiro evidenciam esse dado do nosso estudo, que destaca como um dos aspectos que mais chamam a atenção dos PMs em relação à característica do jovem a moda e a aparência. A população pesquisada por Silvia Ramos e Leonarda Musumeci (2005, p. 209) menciona que as abordagens policiais são, de um modo geral, seletivas e discriminatórias. Dos pesquisados, $60 \%$ consideravam que a polícia selecionava para abordagem com base na aparência física, incluindo nesse dado a cor da pele e o modo de vestir. Outro dado que corrobora nossa análise é o de que $80 \%$ dos cariocas achavam que os jovens eram os mais abordados se comparados com outras faixas etárias.

0 depoimento de um dos oficiais da PM, entrevistado na referida pesquisa, evidencia o que explicitamos: "A cor, num primeiro momento, pode ser importante para a abordagem. Num primeiro momento, na primeira observação, mas o mais importante é a apresentação pessoal" (Ramos; Musumeci, 2005, p. 218).

0 que significa efetivamente uma apresentação pessoa"? Ela não estaria eivada de estereótipos que suscitam procedimentos discriminatórios, intimidatórios, humilhantes, injustos e duvidosos? Não haveria nessa ótica uma violação do direito do jovem?

Assevera-se aqui a afirmação simmeliana de que, do ponto de vista sociológico, a moda é um produto de separação de classe social, ela significa, “[...] por um lado, o 
pertencimento em relação àqueles que estão na mesma situação, e, por outro, o distanciamento do grupo como um todo em relação aos que se situam abaixo socialmente" (Simmel, 2005, p. 161).

\section{Outras visões dos PMs sobre o jovem}

As características positivas foram pouco apontadas. Apenas 10,7\% dos PMs apontaram a consciência, a responsabilidade e o compromisso em primeiro lugar, enquanto 18,2\% dos PMs incluíram esse mesmo item entre as três principais opções que caracterizam a juventude. Apenas $2 \%$ dos PMs apontaram o ser criativo/empreendedor, e 7,5\% apontaram essas características entre as três principais.

Não foram verificadas variações significativas dentre os respondentes em relação à escolaridade e tempo de serviço na corporação quando observamos o destaque às opções que caracterizavam aspectos positivos da juventude.

Todavia, em relação à idade dos respondentes, quando analisamos as características positivas apontadas para os jovens, podemos destacar: quanto à opção "consciência, responsabilidade e compromisso" aparece em primeiro lugar para $9,8 \%$ dos respondentes com até 29 anos de idade, e para 11,8\% está entre as três primeiras. Já para os maiores de 36 anos, aparece em primeiro lugar para 5,6\%, e para 22,3\%, entre as três primeiras.

Quanto à opção ser criativo/empreendedor, esta característica positiva foi pouco referenciada. No entanto, aparece em primeiro lugar para 1,5\% dos respondentes, e para $7,5 \%$ está entre as três primeiras. Dentre os respondentes com até 29 anos de idade, não aparece em primeiro lugar, situando-se apenas para 7,4\% entre as três primeiras. Dentre os respondentes com mais de 36 anos, $2 \%$ consideram-na a principal característica, e 5,9\% elenca-a entre as três primeiras.

Nesse sentido, podemos inferir que, quanto mais jovem o PM, talvez por maior contato com o grupo e/ou por empatia, mais ele indicou a opção consciência, responsabilidade e compromisso como característica do jovem, sendo que a opção ser criativo/ empreendedor foi pouco referenciada, além de não apresentar variação significativa de acordo com a idade do respondente.

As características negativas foram muito apontadas. Para efeitos de análise, classificamos os seguintes itens do questionário como características negativas: a insegurança pessoal e social; a falta de perspectivas; ser transgressor/ousado; ser instável emocionalmente e ser egoísta. Quatro dos itens negativos foram fortemente referidos. Ser transgressor/ousado foi apresentado como opção para caracterizar o jovem hoje por $43,8 \%$ dos respondentes, seguido pela característica de falta de perspectivas, 41,3\%; 
ser instável emocionalmente, 32,2\% dos PMs; e 13,2\% deles destacaram a insegurança pessoal e social. No entanto, das características classificadas como negativas, a opção ser egoísta foi apontada apenas por $2 \%$ dos PMs em primeiro lugar, e por $7 \%$ dos PMs entre as três mais importantes.

Desagregando os dados conforme a escolaridade dos PMs, podemos destacar que a atribuição de características negativas para o jovem obteve variações significativas apenas no item falta de perspectivas, o qual apresentou entre os respondentes com Ensino Médio o percentual de $43,6 \%$ entre as três opções mais citadas. Para os respondentes com Educação Superior o percentual foi de 35,2\% entre as três opções mais assinaladas.

Conclui-se que, de modo geral, o grau de escolaridade não interfere positivamente na definição do jovem. Já em relação à percepção negativa na definição do jovem, verifica-se que está inversamente relacionada ao grau de escolaridade. Quanto maior o grau de escolaridade, menor a visão negativa do PM em relação ao jovem.

Em relação à idade dos respondentes e à apresentação de características negativas para o jovem, podemos destacar que, no grupo das características negativas, destacaram-se a insegurança pessoal e social; a falta de perspectivas; e ser instável emocionalmente. Verificamos que elas foram referidas, em média, por $24,5 \%$ dos PMs com mais de 36 anos de idade, contra $42,5 \%$ dos mais jovens. Diante desses dados, podemos afirmar que, quanto mais jovem o PM, mais ele atribuiu características negativas aos jovens.

Os dados da nossa investigação vão ao encontro dos resultados de outra pesquisa, realizada também com cerca de 290 PMs do Batalhão Escolar do Distrito Federal, sobre as representações sociais de adolescentes, jovens e PMs sobre os adolescentes e seus direitos. A título de ilustração, tomemos desta pesquisa os dados da resposta a uma pergunta. Frente à indagação o que o (a) adolescente está fazendo, das 230 situações descritas pelos PMs, 59,6\% eram ações ilícitas como vandalismo, furto, uso de drogas, promiscuidade e prostituição, e outras. 0 restante das indicações dos PMs apresentou atividades responsáveis, 19,1\% afirmaram estudando e trabalhando; também 19,1\% afirmaram atividades de diversão e lazer, como namorando, paquerando, praticando esporte, estando com amigos, em bares, festas, etc.; 2,2\% indicaram que o adolescente está sofrendo (Paixão, 2008, p.160; 191).

Cabe aqui uma observação sobre o que revela essa visão majoritariamente negativa dos adolescentes e jovens por parte dos PMs: trata-se de uma visão tradicional onde se destacam apenas ou, sobretudo, os aspectos negativos. Dessa forma, descura-se de aspectos culturais imprescindíveis para uma atenta e crítica visão dos processos de socialização dos adolescentes e jovens. 


\section{Considerações finais}

Parece-nos cada vez mais atual a afirmação de Bobbio (1992, p. 24) ao mencionar que o problema central e contemporâneo dos direitos humanos não está na questão de justificá-los, mas em efetivar e protegê-los, pois "trata-se de um problema não filosófico, mas político".

Vimos que o grupo pesquisado dos PMs possui uma alta escolaridade relativa, experiência, é muito motivado e, em parte, jovem. Tais características, se comparadas à literatura existente, demonstram uma interessante associação entre as variáveis experiência, grau de escolaridade e motivação. Todavia, não nos foi possível e não estava no horizonte de nossos objetivos, com base nos dados da investigação, verificar se policiais com educação superior são menos autoritários, têm maior capacidade de expressão, fazem menor uso da força física e da coerção verbal, conforme aponta pesquisa americana (Paoline III; Terrill, 2007). Contudo, os nossos dados nos possibilitam algumas leituras que sugerem confluência de alguns desses dados com a referida pesquisa, mas certamente necessitarão de novas investigações, se assim se desejar maior precisão e detalhamento.

Diante dos dados apresentados e analisados de parte de nossa pesquisa junto aos PMs do Batalhão Escolar da Polícia Militar do Distrito Federal, pudemos constatar que os pesquisados veem como principal característica do jovem a moda e a aparência, e também destacaram outras características predominantemente negativas, como a insegurança pessoal e social; a falta de perspectivas; ser transgressor/ousado; ser instável emocionalmente; ser egoísta.

Sobre a indicação da moda e da aparência como o que mais caracteriza o jovem, verificou-se a relação inversamente proporcional entre o grau de escolaridade e a indicação desta opção, isto é, quanto menos escolaridade, mais se caracteriza a juventude a partir da moda e da aparência.

Ainda sobre esse item, observamos que, quanto maior o tempo de corporação, mais acentuada foi a indicação de moda e aparência como definidoras do jovem nos dias atuais. Há notoriamente, nesses dados, indicadores de uma influência da instituição militar em seus processos de formação e socialização formal e informal, em algum grau, para o endosso dessa visão.

Vimos também que, de modo geral, o grau de escolaridade não interfere positivamente na definição do jovem. Já em relação às percepções negativas na definição do jovem, verificou-se que está inversamente relacionada ao grau de escolaridade. Quanto maior o grau de escolaridade, menor a visão negativa do PM em relação ao jovem. Outra constatação é a de que, quanto mais jovem o PM, mais ele atribui características negativas aos jovens. 
Se, por um lado, os PMs atribuem majoritariamente a moda e a aparência como principais opções para caracterizar o jovem de hoje, por outro lado, esses jovens leem a forma dos PMs vê-los como estereotipada e enviesada. Essa forma enviesada e estereotipada leva os PMs, em certos casos, a praticar arbitrariedades na relação com o jovem, conforme outra pesquisa feita sobre a violência na ótica dos estudantes de escolas públicas e particulares no Distrito Federal (Gomes et al., 2006, p. 29).

Sendo os PMs, notadamente do Batalhão Escolar da Polícia Militar - os atores mais visíveis do Estado quando se pensa em Segurança Pública - é fundamental que estes possam, em seus processos formativos, não apenas conhecerem, mas também exercitarem o fato de que os fatores culturais da pluralidade social e diversidade humana se constituem elementos fundamentais para um diálogo em vista da diminuição das desigualdades sociais no relacionamento entre indivíduo e Estado, especialmente entre os grupos sociais mais afetados pela violência, que certamente inclui os jovens, como verifica reiteradamente a literatura (Waiselfisz et al., 1994; Waiselfisz, 2004).

Tais formação e prática são inadiáveis, pois a diminuição da distância entre a polícia e os grupos por ela mais visados depende de ações que revertam as percepções negativas baseadas em estereótipos e preconceitos para gerar violência. Podemos concluir que policiais e grupos sociais, como os jovens, se percebem por meio de lentes simplificadoras e desfavoráveis, mas a realidade é muito mais complexa. Sem ingenuidade, é preciso construir pontes bilaterais de comunicação. Nesse sentido, há de se incentivar o surgimento e de se potencializar propostas formativas e políticas que promovam maior abertura da organização militar à mudança de filosofias de distanciamento para filosofias do policiamento de proximidade, e similares, que se caracterizam, conforme Matrofski (2002), como uma revolução silenciosa nessas organizações.

Este estudo, embora parta de uma realidade brasileira, pode ser também extensivo a outras realidades, na medida em que apresenta elementos que contribuem para melhor entendimento das realidades e desafios do papel da polícia em suas relações com os vários grupos sociais ao construir leituras da atividade policial, como menciona Durão (2009) em seus estudos sobre as atividades da polícia em Portugal, ou ainda sobre as abordagens policiais na Inglaterra e País de Gales (Bowling; Phillips, 2007).

Por fim, vale a pena lembrar, como afirma Bobbio (1992, p. 1), que "[...] sem direitos humanos reconhecidos e protegidos, não há democracia; sem democracia não existem as condições mínimas para a solução pacífica dos conflitos". Se é verdade que há necessidade de se moldar a cultura policial, bem como a da sociedade, aos valores da democracia, há de igualmente se contemplar uma questão óbvia: a cultura da formação dos formadores também deve estar em consonância com esses valores.

Advogamos que a assunção de tal cultura está fundada no pilar do acesso à Justiça, ou melhor, na resolução ética e ordenada dos conflitos existentes em sociedades 
complexas. Uma cultura democrática de direitos humanos não pode garantir a supressão de todo e qualquer conflito social - e talvez nem devesse fazê-lo -, mas deve ensejar a garantia de que todo e qualquer problema possa ser resolvido com justiça, que as necessidades fundamentais possam ser vindicadas perante uma comunidade de sujeitos de direitos (SOUSA, 2004). A juventude não pode, por sua aparência, ter seus direitos negados por aqueles que a deveriam proteger.

\section{Referências}

ABRAMOVAY, Miriam et al. Gangues, galeras, chegados e rappers: juventude, violência e cidadania nas cidades da periferia de Brasília. Rio de Janeiro: Garamond, 1999.

BRASIL. Constituição (1988). Constituição da República Federativa do Brasil. 24. ed. São Paulo: Saraiva, 2000.

BOBBIO, Norberto. A Era dos Direitos. Rio de Janeiro: Campus, 1992.

BOWLING, Ben; PHILLIPS, Coretta. Disproportionate and Discriminatory: Reviewing the Evidence on Police Stop and Search. Modern Law Review, v. 70, n. 6, p. 936-961, November 2007. Disponível em: <http://papers.ssrn.com/sol3/papers.cfm?abstract_id=1024344 > Acesso em: 23 jul. 2011.

BROWN, Ben; BENEDICT, Wm Reed; WILKINSON, William V. Public perceptions of the police in Mexico: a case study. Policing: International Journal of Police Strategies \& Management, Bigley, UK, v. 29, n. 1, p. 158-175, 2006.

COPELAND, Anna. Participation and the role of public space: our space, their space and my space. Public Space: The Journal of Law and Social Justice, Sydney, Austrália, v. 2, n. 4, p. 1-28, 2008. Disponível em: <http://www.austlii.edu.au/au/journals/PubSpace/2008/5.pdf>. Acesso em: 30 out. 2011.

DELORS, Jacques et al.. Educação: um tesouro a descobrir. Relatório para a UNESCO da Comissão Internacional sobre Educação para o Século XXI. 4. ed. São Paulo: Cortez; Brasília: MEC, UNESCO, 2000.

DURÃO, Susana. A produção de mapas policiais: Práticas e políticas da polícia urbana em Portugal. Intersecciones antropol., Olavarría, v. 10, n. 1, jun. 2009. Disponível em: <http://www.scielo.org.ar/ scielo.php?script=sci_arttext\&pid=S1850-373X2009000100004\&lng=es\&nrm=iso>. Acesso em: 26 jun. 2010.

GALLAND, Olivier. Sociologie de la jeunesse. Paris: Armand Collin, 1997.

GELMAN, Andrew; FAGAN, Jeffrey; KISS, Alex. An analysis of the NYPD's stop-and-frisk policy in the context of claims of racial bias. Journal of the American Statistical Association, Alexandria, Virginia, v. 102, n. 479, p. 813-823, Sep. 1, 2007.

GOMES, Candido Alberto (Org.). Juventudes: possibilidades e limites. Brasília: UNESCO, Cátedra UNESCO de Juventude, Educação e Sociedade da Universidade Católica de Brasília, Secretaria Nacional de Juventude da Presidência da República, 2011. Disponível em: <http://unesdoc.unesco.org/ images/0019/001923/192357por.pdf>. Acesso em: 30 out. 2011. 
GOMES, Candido Alberto et al. A violência na ótica de alunos adolescentes do Distrito Federal. Cad. Pesqui., São Paulo, v. 36, n. 127, abr. 2006 . Disponível em <http://www.scielo.br/scielo.php?script =sci_arttext\&pid=S0100-15742006000100002\&lng=pt\&nrm=iso>. Acesso em: 26 jun. 2010.

GUILLOT, Gérard. O resgate da autoridade em educação. Porto Alegre: Artmed, 2008.

HAGAN, John; SHEDD, Carla; PAYNE, Monique R. Race, ethnicity, and youth perceptions of criminal injustice. American Sociological Review, v. 70, p. 381-407, Jun. 2005.

HURST, Yolander G.; McDERMOTT, M. Joan; THOMAS, Deborah L. Attitudes of girls toward the police: differences by race. Policing: an International Journal of Police Strategies \& Management, Bigley, v. 28, n. 4, p. 578-593, 2005.

IANNI, Octavio. O jovem radical. Rio de Janeiro: Zahar, 1968. (Sociologia da Juventude, v. 1)

LEHNERT, Gertrud. Geschichte der Mode: des 20 Jahrhunderts. Köln: Könemann, 2000.

MATROFSKI, Stephen D. Policiamento Comunitário e Estrutura da Organização Policial. In: BRODEUR, Jean-Paul (Org.). Como reconhecer um bom policiamento: problemas e temas. São Paulo: Edusp, 2002. (Série Polícia e Sociedade, n. 6).

MINAYO, Maria Cecília de Souza et al. Fala Galera: juventude, violência e cidadania na cidade do Rio de Janeiro. Rio de Janeiro: Garamond, 1999.

NUÑEZ, Pedro. Patrullando la ciudad. Política e Sociedade: Revista de Sociologia Política, Florianópolis, v. 5, n. 8, p. 159-189, 2006. Disponível em: <http://www.periodicos.ufsc.br/index.php/politica/article/ view/1807/1566>. Acesso em: 30 out. 2011.

PAIXÃO, Divaneide Lira Lima. Direitos humanos e adolescência no contexto de uma sociedade violenta: um estudo de representações sociais. 2008. Tese (Doutorado em Psicologia Social) - Departamento de Psicologia, Universidade de Brasília (UnB), Brasília, 2008.

PAOLINE III, Eugene A.; TERRILL, William. Police Education, experience and the use of force. Criminal Justice and Behavior, Glenville, v. 34, n. 2, p. 179-196, fev. 2007.

POMMEREAU, Xavier. Les marques cutanées à l'adolescence. Le Journal des Psychologues, Paris, n. 243, p. 71-75, 10/2006. Disponível em : <http://www.cairn.info/revue-le-journal-des-psychologues2006-10-page-71.htm>. Acesso em: 30 out. 2011.

QUEIROZ, Valda Maria de. O eterno no transitório... um estudo sociológico da moda. 2002. Tese (Doutorado em Sociologia) - Departamento de Sociologia, Universidade de Brasília (UnB), Brasília, 2002.

RAMOS, Silvia; MUSUMECI, Leonarda (Org.). Elemento suspeito: abordagem policial e discriminação na cidade do Rio de Janeiro. Rio de Janeiro: Civilização Brasileira, 2005.

RIST, Ray. On understanding the process of schooling: the contributions of the labeling theory. In: KARABEL, Jerome; HALSEY, A. H. (Ed.). Power and ideology in education. Nova lorque: Oxford University Press, 1978. p. 292-306.

SAVAGE, Jon. A criação da juventude: como o conceito de teenage revolucionou o século XX. Rio de Janeiro: Rocco, 2009.

SIMMEL, Georg. Da psicologia da moda: um estudo sociológico. In: SOUZA, Jesse. e ÖELZE, Berthold. (Org.). Simmel e a Modernidade. 2. ed. Brasília: Editora da UnB, 2005. p.159-168.

SOUSA, Carlos Ângelo de Meneses. Cidadania e Direitos Humanos: uma experiência da Coordenadoria 
de Cidadania e Direitos Humanos da Universidade Católica de Brasília. In: CONGRESSO INTERNACIONAL DE EDUCAÇÃO/CONGRESSO DE PESQUISA EM EDUCAÇÃO DA UNIVERSIDADE FEDERAL DO PIAUÍ, 2., 3., 2004, Piauí. Livro Resumo do // Congresso Internacional de Educação/III Congresso de Pesquisa em Educação. Teresina: EDUFPI, 2004.

STALLYBRASS, Peter. 0 casaco de Marx: roupas, memória, dor. 2. ed. Belo Horizonte: Autêntica, 2000. WAISELFISZ, Júlio J. Mapa da Violência IV: Os Jovens do Brasil. Brasília: UNESCO, 2004. Disponível em: $\quad$ http://www.desarme.org/publique/media/Mapa\%20da\%20viol\%C3\%AAncia\%20IV\%20\%20Unesco.pdf>. Acesso em: 22 jun. 2010.

. et al.. Juventude, violência e cidadania: os jovens de Brasília. São Paulo: Cortez; Brasília: UNESCO, 1998.

Recebido em agosto de 2011.

Aprovado em outubro de 2011.

Carlos Angelo de Meneses Sousa, doutor em Sociologia pela Universidade de Brasília (UnB). Professor do Programa de Pós-graduação em Educação da Universidade Católica de Brasília (UCB). Pesquisador da Cátedra UNESCO de Juventude, Educação e Sociedade/UCB - Brasil. Publicou em janeiro de 2011 na revista Interacções (Portugal) o artigo "Novas Linguagens e Sociabilidades: como uma juventude vê novas tecnologias". E-mail: cangeloducb.br

Candido Alberto da Costa Gomes, doutor em Educação pela University of Califórnia, Los Angeles (Estados Unidos). Professor Titular do Programa de Pós-graduação em Educação da Universidade Católica de Brasília (UCB), vice-coordenador da Cátedra UNESCO de Juventude, Educação e Sociedade/ UCB - Brasil. Uma das mais recentes publicações, em 2011, foi a organização do livro "Juventudes: possibilidades e limites" editado pela UCB/UNESCO. E-mail: clgomesQterra.com.br 